


\section{Impact of probiotic intake on the glycemic control, lipid profile and inflammatory markers among patients with type 2 diabetes mellitus}

\section{ABSTRACT}

Background. Type 2 diabetes mellitus (T2DM) is a chronic disease with many dramatic complications. It has also been suggested that altered intestinal microbiota leads to increased intestinal permeability and mucosal immune response, contributing to the development of diabetes. We aimed to investigate the effect of introduction of probiotic products on glycemic control and inflammatory markers among patients with T2DM.

Methods. The present work was carried on 150 patients with T2DM. The studied patients were subjected to full history taking, clinical examination and laboratory investigations including fasting blood glucose (FBG), 2 hours post prandial blood glucose ( $2 \mathrm{hPP}$ ), glycated hemoglobin (HbA1c), total cholesterol (TC), triglycerides (TG), HDL-C, LDL-C, C-reactive protein (CRP), interleukin 6 (IL6) and tumor-necrosis factor alpha (TNF ). They were divided into 3 groups each of 50 patients. They were all instructed to eat well-balanced diet. The first group was instructed to eat the well-balanced diet only, the second group received 2 cups of yogurt daily in addition to diet and the third group received one teaspoonful yeast daily in addition to diet. The effect

Address for correspondence:

Azza A. Ismael.

Address: Ramlh station, Alexandria, Egypt

tel.: 00201220509611

e-mail: dr_azzak@yahoo.com

Clinical Diabetology 2021, 10

DOI: 10.5603/DK.a2021.0037

Received: 3.01.2021

Accepted: 8.03.2021 of the intervention was evaluated after 16 weeks. Results. Patients receiving yogurt and the patients receiving yeast showed significant reduction of FBG, HbA1C, IL6, TNF- $\alpha$, CRP and significant elevation of HDL-C compared to patients on diet only. The 3 groups showed significant reduction in $2 \mathrm{hPP}$ blood glucose and LDL-C.

Conclusion. Probiotic intake in patients with T2DM has beneficial effect on glycemic control, lipid profile and inflammatory markers after 16 weeks. (Clin Diabetol $2021 ; 10)$

Key words: type 2 diabetes, probiotics, lipid profile, inflammatory markers, yeast

\section{Introduction}

Diabetes mellitus is one of the most common chronic diseases in nearly all countries, and continues to increase in number and significance, especially with changing lifestyles leading to reduced physical activity and increased obesity [1, 2].

Type 2 diabetes mellitus (T2DM) is a metabolic disorder characterized by hyperglycemia in addition to altered lipid and protein metabolism caused by variable degrees of insulin resistance, impaired insulin secretion and increased glucose production $[3,4]$.

Accumulating evidence shows that inflammation plays a crucial intermediary role in the pathogenesis of T2DM, thus relating diabetes to a number of commonly coexisting conditions thought to originate via inflammatory mechanisms [5]. In this regard, more data suggest that interleukin-6 (IL-6) and C-reactive protein 
(CRP) are associated with type 2 diabetes [6]. Several studies indicated that increased levels of cytokines and acute-phase proteins can participate in maintaining the insulin-resistant state [7-10].

T2DM affects the immune system of the body and these immunological changes affect the cytokine release which alter the leukocytes and result in increased apoptosis. These changes suggest the involvement of inflammation in the pathogenesis of T2DM [11]. Proinflammatory cytokines and acute phase reactants are involved in multiple metabolic pathways relevant to insulin resistance, including insulin regulation, reactive oxygen species, lipoprotein lipase action and adipocyte function [12]. Inflammation is considered as a key factor in the pathogenesis of T2DM, but what triggers this inflammation is still unknown; however, obesity is considered an important factor [13, 14].

The gut microbiota comprises approximately $10^{14}$ organisms, which in human adults are mainly represented by members of the phyla: bacteroides, sclerenchyma, actinomycetes, proteus, and verrucous microflora. The exact microbiome composition varies greatly between individuals [15]. Gut microbes are key to many aspects of human health, including immune and metabolic functions, and evidence supports the important role of gut microbiota in human health $[16,17]$.

Homeostasis of microbiota in the gut is vital for maintenance of the host immunity and there has been evidence demonstrating that changes in the composition of gut microbiota could play a role in the pathogenesis of T2DM [18, 19]. Dysbiotic gut microbiota affects gut permeability and promotes inflammation in T2DM as the intestinal barrier is disturbed by microbial product - lipopolysaccharide (LPS). The LPS released from the gut into the circulation causes "metabolic endotoxemia" which is a state of low-grade systemic inflammation [18, 20, 21].

Yeasts are eukaryotic microorganisms classified as members of the fungus kingdom with 1,500 species currently identified and are estimated to constitute $1 \%$ of all described fungal species [22]. Yeasts are unicellular, although some species may also develop multicellular characteristics by forming strings of connected budding cells known as pseudohyphae or false hyphae [22].

Probiotics are live microorganisms that, when administered in adequate amounts, confer a health benefit on the host [23]. While most well-characterized probiotic microbes are bacteria, certain yeasts have been shown to have health benefits across various studies [24]. Different yeast species such as Saccharomyces cerevisiae, Saccharomyces boulardi and some strains of Candida are recognized as yeasts with probiotic potential $[25,26]$. Evidence is available on the anti-inflammatory properties of probiotics and some researches showed beneficial use of probiotics in T2DM [27]. Animal studies showed that Lactobacillus GG treatment not only reduces glucose intolerance but also significantly decrease hyperglycemia in streptozotocin induced diabetes rats [28]. It has also been demonstrated that probiotics can decrease the blood glucose in animal models through reduction of inflammation and prevention of $\beta$-cell destruction [29]. Yun et al. [30] reported a significant reduction in fasting and postprandial glucose and a decrease in $\mathrm{HbA} 1 \mathrm{c}$ in probiotic treated rats. However, human clinical studies using various probiotics have yielded mixed results. A meta-analysis by Yao et al. [31] demonstrated that probiotics supplementation was associated with significant improvement in $\mathrm{HbA}_{1 \mathrm{c}}$ and fasting insulin in patients with T2DM. Other meta-analyses revealed that probiotic supplementation beneficial affects insulin resistance and glycated hemoglobin levels [32, 33].

The aim of this study was to assess the effect of probiotic yoghurt and yeast intake on the inflammatory markers, glycemic control and lipid profile among patients with T2DM.

\section{Material and methods}

The study was carried out on 150 patients with T2DM and the duration of the study was 16 weeks. The study included male and female patients aged 21 years and older with T2DM who agreed to participate in this study. The cases were recruited from the outpatient clinic of diabetes in Alexandria Main University Hospital. Patients with coronary heart diseases, history or presence of cancer, patients with lactose intolerance, patients with thyroid disorders, and pregnant and lactating women were excluded from this study.

All the participants included in the study were informed about the nature of the study, and their oral and written consent on participating voluntarily were obtained and the approval of ethics committee of Alexandria faculty of medicine was also obtained.

Full medical history, drug history (nutritional supplements, drugs of weight reduction and drugs for chronic diseases), diabetes history (age of onset of the disease, drugs taken, trials of diet regimens and family history of diabetes) and finally dietary habits (number of main meals and snacks, fast-food consumption, and fat consumption) were obtained from all studies subjects. Anthropometric measurements were done including height, weight, body mass index (BMI) and waist circumference.

The 150 diabetic patients were divided into 3 groups with 50 persons in each group. Patients in 
Group 1 were instructed by the researcher to eat well balanced diet, based on the subject's measured pretreatment resting energy expenditure, designed to provide $45-65 \%$ of energy from carbohydrates, $10-35 \%$ of energy from proteins and $20-35 \%$ of energy derived from fat. The resting energy expenditure is estimated using the Mifflin-St Jeor equation [34]. Subjects were advised to exercise or walk 30 minutes per day, five days a week. Group 2, the same as the first group plus the intake of two cups of yogurt provided by the researchers daily. The yogurt used in the study was fortified by probiotic strains (Bifidobacterium animalis $d n-173010)$. Group 3, the same as the first group plus a supplement in the form of one teaspoonful of natural baking yeast daily containing Saccharomyces cerevisiae before lunch, provided by the researchers. Group 1 was considered as the control group while groups 2 and 3 were considered to be the experimental groups.

Laboratory investigations were performed for every patient at the beginning and after 8 and 16 weeks of the study including fasting blood glucose level ( FBG), two hours post prandial blood glucose level (2hPP) which was performed 2 hours after breakfast using a sample of venous blood, total cholesterol (TC) and triglyceride (TG) serum level, HDL-C, LDL-C levels, Creactive protein (CRP) level, interleukin 6 (IL6) level, tumor necrosis factor alpha (TNF ) level and glycated hemoglobin (HbA1c).

After 16 weeks of the study, reassessment of the change of the outcome after the intervention on the anthropometric measurements and all parameters of laboratory investigations were performed.

\section{Results}

The studied subjects were divided into 3 groups. There was no significant difference between studied groups regarding age and male to female ratio. The basic characteristics of the studied subjects are described in Table 1.

As shown in Tables 2 and 3, after 16 weeks of intervention the three groups showed significant reduction in the 2 hours postprandial blood glucose level but the reduction was higher among yogurt and yeast groups compared to diet only $(\mathrm{P}<0.001, \mathrm{P}<0.001$ respectively) and there was no significant difference between yogurt group and yeast group $(P=0.836)$. However, only the patients receiving yogurt and the patients receiving yeast showed significant reduction in FBG and $\mathrm{HbA} 1 \mathrm{c}$ levels with no significant difference in reduction in FBG and $\mathrm{HbA} 1 \mathrm{c}$ between both groups $(P=0.933, P=0.397$ respectively) while there was no significant change in FBG and $\mathrm{HbA} 1 \mathrm{c}$ levels in patients receiving diet only.
Regarding the lipid profile, after 16 weeks, the three groups showed significant reduction in the level of total cholesterol and LDL-C levels but the reduction in total cholesterol was higher in yogurt and yeast groups compared to diet only $(P<0.001, P<0.001$ respectively) and there was no significant difference in the reduction of LDL-C among the three groups. Only the patients receiving yogurt and the patients receiving yeast showed significant rise in HDL-C levels with no significant difference in elevation of HDL-C between both groups $(P=0.948)$ while there was no significant change in HDL-C level in patients receiving diet only. On the other hand, patients receiving yogurt in addition to diet showed significant reduction in serum triglycerides level while there was no significant change in the triglyceride level in the other 2 groups.

Regarding the inflammatory markers, after 16 weeks, the patients receiving yogurt and the patients receiving yeast showed significant reduction in CRP level, IL-6 level, and TNF- $\alpha$ levels, but there was no significant change in their levels in patients receiving diet only. There was no significant difference between the yogurt and yeast groups regarding reduction in CRP and IL-6 levels ( $\mathrm{P}=0.557$, and $\mathrm{P}=0.807$ respectively) while the reduction in TNF- $\alpha$ was higher in patients receiving yogurt compared to those receiving yeast $(P<0.001)$.

\section{Discussion}

Recent studies indicate that gut microbiota play an important role in the pathogenesis of T2DM. As an effective means of regulating gut microbiota, probiotics are live micro-organisms that are believed to provide a specific health benefit on the host. Whether probiotic supplementation could improve metabolic profiles by modifying gut microbiota in T2DM or not is still controversial [35].

The gut microbiota could influence inflammatory pathways and energy metabolism of the host, in other words, dysbiotic gut microbiota could affect glucose, lipid metabolism, and insulin action [36, 37]. More and more studies showed that probiotics could change the gut flora, improve total cholesterol and low-density lipoprotein cholesterol levels, and reduce blood glucose level and insulin resistance [37-39].

In the current study, efforts were done to record the effect of intake of different types of probiotics on many parameters of patients with T2DM through the introduction of two types of probiotics using yogurt and yeast. The yoghurt used in the study contained a probiotic strain known as Bifidobacterium animalis $d n-173$ 010 and the yeast contained Saccharomyces cerevisiae.

In our study, there was a statistically significant reduction in FBG, 2 hPP glucose level and glycated 
Table 1. Basic characteristics of the studied groups

\begin{tabular}{|c|c|c|c|c|c|c|}
\hline & $\begin{array}{l}\text { Yogurt and diet } \\
\qquad(n=50)\end{array}$ & $\begin{array}{l}\text { Yeast and diet } \\
\qquad(n=50)\end{array}$ & $\begin{array}{l}\text { Diet only } \\
(n=50)\end{array}$ & $\mathbf{P}_{1}$ & $\mathbf{P}_{2}$ & $\mathbf{P}_{3}$ \\
\hline \multicolumn{7}{|l|}{ Age (years) } \\
\hline Mean \pm SD & $48.3 \pm 12.9$ & $48.6 \pm 11.5$ & $46.4 \pm 13.2$ & 0.992 & 0.730 & 0.656 \\
\hline \multicolumn{7}{|l|}{ Weight [kg] } \\
\hline Mean \pm SD & $86.7 \pm 15.3$ & $81.8 \pm 14.9$ & $89 \pm 16$ & 0.260 & 0.733 & 0.055 \\
\hline \multicolumn{7}{|l|}{ BMI $\left[\mathrm{kg} / \mathrm{m}^{2}\right]$} \\
\hline Mean \pm SD & $31.1 \pm 5.3$ & $28.5 \pm 7.6$ & $30.2 \pm 6$ & 0.102 & 0.765 & 0.363 \\
\hline \multicolumn{7}{|l|}{ FBG [mg/dL] } \\
\hline Mean $\pm S D$ & $139.6 \pm 33.1$ & $137.5 \pm 32.6$ & $136 \pm 24$ & 0.937 & 0.823 & 0.966 \\
\hline \multicolumn{7}{|l|}{$2 \mathrm{hPP}[\mathrm{mg} / \mathrm{dL}]$} \\
\hline Mean \pm SD & $224.2 \pm 38.7$ & $231 \pm 34.7$ & $221.8 \pm 18.4$ & 0.539 & 0.925 & 0.323 \\
\hline \multicolumn{7}{|l|}{$\mathrm{HbA}_{1 \mathrm{c}}(\%)$} \\
\hline Mean $\pm S D$ & $8.2 \pm 1.4$ & $8.2 \pm 1.4$ & $8 \pm 1.2$ & 0.999 & 0.610 & 0.638 \\
\hline \multicolumn{7}{|c|}{ Total cholesterol [mg/dL] } \\
\hline Mean \pm SD & $273.8 \pm 49.3$ & $272.5 \pm 25.9$ & $268 \pm 25.9$ & 0.981 & 0.689 & 0.800 \\
\hline \multicolumn{7}{|l|}{ TG [mg/dL] } \\
\hline Mean \pm SD & $179 \pm 39.9$ & $177.2 \pm 29.4$ & $166.3 \pm 23.9$ & 0.959 & 0.115 & 0.199 \\
\hline \multicolumn{7}{|l|}{ HDL-C [mg/dL] } \\
\hline Mean \pm SD & $43.4 \pm 3.3$ & $43.6 \pm 4.1$ & $45.1 \pm 5.5$ & 0.972 & 0.113 & 0.178 \\
\hline \multicolumn{7}{|l|}{ LDL-C [mg/dL] } \\
\hline Mean \pm SD & $121.4 \pm 17.5$ & $118.4 \pm 16.5$ & $114.7 \pm 5.7$ & 0.553 & 0.053 & 0.394 \\
\hline \multicolumn{7}{|l|}{ CRP [mg/dL] } \\
\hline Mean \pm SD & $10.8 \pm 5.2$ & $10.9 \pm 3.8$ & $9.2 \pm 3.3$ & 0.204 & 0.439 & 0.025 \\
\hline \multicolumn{7}{|l|}{ IL6 [mg/dL] } \\
\hline Mean $\pm S D$ & $50.2 \pm 24.3$ & $43.1 \pm 15.7$ & $43.5 \pm 14.9$ & 0.432 & 0.605 & 0.815 \\
\hline \multicolumn{7}{|l|}{$\mathrm{TNF}-\alpha[\mathrm{mg} / \mathrm{dL}]$} \\
\hline Mean \pm SD & $21.2 \pm 4.5$ & $20.2 \pm 3$ & $17.3 \pm 0.5$ & 0.609 & 0.001 & 0.001 \\
\hline
\end{tabular}

2hPP: 2 hours postprandial blood glucose; BMl: body mass index; CRP: C-reactive protein; FBG: fasting blood glucose; HbA1c: glycated hemoglobin; HDL-C: high-density lipoprotein cholesterol; IL-6: interleukin 6; LDL-C: low-density lipoprotein cholesterol; TG: triglycerides; TNF- : tumor necrosis factor alpha $\mathrm{P}_{1}: \mathrm{P}$ value for comparing between Yogurt and diet group and Yeast and diet group

$P_{2}$ : $P$ value for comparing between Yogurt and diet group and Diet only group

$P_{3}$ : $P$ value for comparing between Yeast and diet group and Diet only group

Statistically significant at $\mathrm{P} \leq 0.0$

hemoglobin level in the patients who received probiotic yogurt alone or yeast on a daily basis.

This partially agrees with a meta-analysis in which a total of 12 randomized controlled trials were included. Probiotics could improve FBG but there were no significant differences in $\mathrm{HbA}_{1 \mathrm{c}}$ and HOMA-IR between the treatment group and the control group [35]. Another meta-analysis of 12 randomized controlled trials concluded that probiotics could reduce FBG levels by around $15 \mathrm{mg} / \mathrm{dL}$ and $\mathrm{HbA} 1 \mathrm{c}$ by $0.54 \%$, along with a significant improvement of 0.98 in HOMA-IR values, indicating a modest effect on glycemic control. This analysis elucidated that probiotics may improve glycemic control in T2DM [33]. Another study by Yun et al. [30] found that probiotic administration of Bifidobacterium for 1 month in mice with high-fat diet-induced diabetes normalized the glucose metabolism. This was documented by the lowering of fasting insulin levels, blunting of glucose excursions on the intraperitoneal glucose tolerance test, and increase in the glucose turnover rate.

In our study total cholesterol and LDL-C levels were reduced in the three groups with higher reduction in total cholesterol in patients receiving probiotics compared to those who didn't receive probiotics. Also, HDL-C levels were elevated in patients receiving yogurt or yeast on a daily basis compared to those who didn't receive them while beneficial effect on triglycerides levels was shown with yogurt only. These data agrees with a study by Ejtahed et al. [40] in which probiotic yogurt consumption caused a $4.54 \%$ decrease in total cholesterol and a $7.45 \%$ decrease in LDL-C compared with the control group. 
Table 2. Effect of the intervention on different studied parameters after 16 weeks

\begin{tabular}{|c|c|c|c|}
\hline & Baseline & After 16 weeks & $\mathbf{P}$ \\
\hline \multicolumn{4}{|l|}{ FBG [mg/dL] } \\
\hline \multicolumn{4}{|c|}{ Yogurt and diet $(n=50)$} \\
\hline Mean \pm SD & $139.6 \pm 33.1$ & $111.3 \pm 21.8$ & $<0.001^{*}$ \\
\hline \multicolumn{4}{|c|}{ Yeast and diet $(n=50)$} \\
\hline Mean \pm SD & $137.5 \pm 32.6$ & $112.9 \pm 24.2$ & $<0.001^{*}$ \\
\hline \multicolumn{4}{|c|}{ Diet only $(n=50)$} \\
\hline Mean \pm SD & $136 \pm 24$ & $133.6 \pm 21.4$ & 1.000 \\
\hline \multicolumn{4}{|l|}{$2 \mathrm{hPP}[\mathrm{mg} / \mathrm{dL}]$} \\
\hline \multicolumn{4}{|c|}{ Yogurt and diet $(n=50)$} \\
\hline Mean \pm SD & $224.2 \pm 38.7$ & $163.3 \pm 25.9$ & $<0.001^{*}$ \\
\hline \multicolumn{4}{|c|}{ Yeast and diet $(n=50)$} \\
\hline Mean \pm SD & $231 \pm 34.7$ & $160.7 \pm 18.3$ & $<0.001^{*}$ \\
\hline \multicolumn{4}{|c|}{ Diet only $(n=50)$} \\
\hline Mean $\pm S D$ & $221.8 \pm 18.4$ & $190.2 \pm 22.5$ & $0.001^{*}$ \\
\hline \multicolumn{4}{|l|}{$\mathrm{HbA}_{1 \mathrm{c}}(\%)$} \\
\hline \multicolumn{4}{|c|}{ Yogurt and diet $(n=50)$} \\
\hline Mean \pm SD & $8.2 \pm 1.4$ & $6.9 \pm 1.3$ & $<0.001^{*}$ \\
\hline \multicolumn{4}{|c|}{ Yeast and diet $(n=50)$} \\
\hline Mean \pm SD & $8.2 \pm 1.4$ & $7.2 \pm 1.3$ & $<0.001^{*}$ \\
\hline \multicolumn{4}{|c|}{ Diet only $(n=50)$} \\
\hline Mean \pm SD & $8 \pm 1.2$ & $8.2 \pm 0.8$ & 0.377 \\
\hline \multicolumn{4}{|c|}{ Total cholesterol (mg/dL) } \\
\hline \multicolumn{4}{|c|}{ Yogurt and diet $(n=50)$} \\
\hline Mean \pm SD & $273.8 \pm 49.3$ & $201.2 \pm 26.6$ & $<0.001^{*}$ \\
\hline \multicolumn{4}{|c|}{ Yeast and diet $(n=50)$} \\
\hline Mean \pm SD & $272.5 \pm 25.9$ & $193 \pm 21.4$ & $<0.001^{*}$ \\
\hline \multicolumn{4}{|c|}{ Diet only $(n=50)$} \\
\hline Mean \pm SD & $268 \pm 25.9$ & $241 \pm 33.4$ & $<0.001^{*}$ \\
\hline \multicolumn{4}{|l|}{$\mathrm{TG}[\mathrm{mg} / \mathrm{dL}]$} \\
\hline \multicolumn{4}{|c|}{ Yogurt and diet $(n=50)$} \\
\hline Mean \pm SD & $179 \pm 39.9$ & $131.6 \pm 26.6$ & $<0.001^{*}$ \\
\hline \multicolumn{4}{|c|}{ Yeast and diet $(n=50)$} \\
\hline Mean \pm SD & $177.2 \pm 29.4$ & $166.1 \pm 26.7$ & 0.073 \\
\hline \multicolumn{4}{|c|}{ Diet only $(n=50)$} \\
\hline Mean \pm SD & $166.3 \pm 23.9$ & $151 \pm 29.2$ & 0.067 \\
\hline \multicolumn{4}{|l|}{$\mathrm{HDL}-\mathrm{C}[\mathrm{mg} / \mathrm{dL}]$} \\
\hline Yogurt and die & & & \\
\hline Mean \pm SD & $43.4 \pm 3.3$ & $55.8 \pm 4.1$ & $<0.001^{*}$ \\
\hline Yeast and diet & & & \\
\hline Mean \pm SD & $43.6 \pm 4.1$ & $55.5 \pm 4.2$ & $<0.001^{*}$ \\
\hline Diet only ( $\mathrm{n}=$ & & & \\
\hline Mean \pm SD & & & \\
\hline LDL-C [mg/dL] & $45.1 \pm 5.5$ & $45.3 \pm 5.1$ & 1.000 \\
\hline Yogurt and die & & & \\
\hline Mean \pm SD & $121.4 \pm 17.5$ & $105.3 \pm 13.2$ & $<0.001^{*}$ \\
\hline Yeast and diet & & & \\
\hline Mean \pm SD & $118.4 \pm 16.5$ & $105.2 \pm 17.5$ & $<0.001^{*}$ \\
\hline Diet only ( $\mathrm{n}=$ & & & \\
\hline Mean \pm SD & $114.7 \pm 5.7$ & $107.7 \pm 7.6$ & $<0.001^{*}$ \\
\hline CRP $[\mathrm{mg} / \mathrm{dL}]$ & & & \\
\hline Yogurt and die & & & \\
\hline Mean $\pm S D$ & $10.8 \pm 5.2$ & $4.6 \pm 2.4$ & $<0.001^{*}$ \\
\hline
\end{tabular}


Table 2. Effect of the intervention on different studied parameters after 16 weeks

\begin{tabular}{|c|c|c|c|}
\hline & Baseline & After 16 weeks & $\mathbf{P}$ \\
\hline \multicolumn{4}{|c|}{ Yeast and diet $(n=50)$} \\
\hline Mean \pm SD & $10.9 \pm 3.8$ & $5 \pm 2.8$ & $<0.001^{*}$ \\
\hline \multicolumn{4}{|c|}{ Diet only $(n=50)$} \\
\hline Mean \pm SD & $9.2 \pm 3.3$ & $8.2 \pm 5.1$ & 0.064 \\
\hline \multicolumn{4}{|c|}{ IL6 [mg/dL] } \\
\hline \multicolumn{4}{|c|}{ Yogurt and diet $(n=50)$} \\
\hline Mean \pm SD & $50.2 \pm 24.3$ & $31.5 \pm 14.4$ & $<0.001^{*}$ \\
\hline \multicolumn{4}{|c|}{ Yeast and diet $(n=50)$} \\
\hline Mean \pm SD & $43.1 \pm 15.7$ & $31.7 \pm 12$ & $<0.001^{*}$ \\
\hline \multicolumn{4}{|c|}{ Diet only $(n=50)$} \\
\hline Mean \pm SD & $43.5 \pm 14.9$ & $43.1 \pm 16.3$ & 0.058 \\
\hline \multicolumn{4}{|l|}{ TNF- $\alpha[\mathrm{mg} / \mathrm{dL}]$} \\
\hline \multicolumn{4}{|c|}{ Yogurt and diet $(n=50)$} \\
\hline Mean \pm SD & $21.2 \pm 4.5$ & $16.5 \pm 1.5$ & $<0.001^{*}$ \\
\hline \multicolumn{4}{|c|}{ Yeast and diet $(n=50)$} \\
\hline Mean \pm SD & $20.2 \pm 3$ & $17.1 \pm 1$ & $<0.001^{*}$ \\
\hline \multicolumn{4}{|c|}{ Diet only ( $n=50)$} \\
\hline Mean $\pm S D$ & $17.3 \pm 0.5$ & $18.1 \pm 0.8$ & 0.055 \\
\hline
\end{tabular}

2hPP: 2 hours postprandial blood glucose; BMI: body mass index; CRP: C-reactive protein; FBG: fasting blood glucose; HbA1c: glycated hemoglobin; HDL-C: high-density lipoprotein cholesterol; IL6: interleukin 6; LDL-C: low-density lipoprotein cholesterol

TG: triglycerides; TNF- $\alpha$ : tumor necrosis factor alpha; *Statistically significant at $p \leq 0.05$

Table 3. Comparison of the laboratory parameters in the three groups after 16 weeks of intervention

\begin{tabular}{|c|c|c|c|c|c|c|}
\hline & $\begin{array}{l}\text { Yogurt and diet } \\
\qquad(n=50)\end{array}$ & $\begin{array}{l}\text { Yeast and diet } \\
\qquad(n=50)\end{array}$ & $\begin{array}{l}\text { Diet only } \\
(n=50)\end{array}$ & $P_{1}$ & $\mathbf{P}_{2}$ & $\mathbf{P}_{3}$ \\
\hline \multicolumn{7}{|l|}{ FBG $[\mathrm{mg} / \mathrm{dL}]$} \\
\hline Mean \pm SD & $111.3 \pm 21.8$ & $112.9 \pm 24.2$ & $133.6 \pm 21.4$ & 0.933 & $<0.001$ & $<0.001$ \\
\hline \multicolumn{7}{|l|}{$2 \mathrm{hPP}[\mathrm{mg} / \mathrm{dL}]$} \\
\hline Mean \pm SD & $163.3 \pm 25.9$ & $160.7 \pm 18.3$ & $190.2 \pm 22.5$ & 0.836 & $<0.001$ & $<0.001$ \\
\hline \multicolumn{7}{|l|}{$\mathrm{HbA}_{1 \mathrm{c}}(\%)$} \\
\hline Mean \pm SD & $6.9 \pm 1.3$ & $7.2 \pm 1.3$ & $8.2 \pm 0.8$ & 0.397 & $<0.001$ & $<0.001$ \\
\hline \multicolumn{7}{|c|}{ Total cholesterol [mg/dt] } \\
\hline Mean \pm SD & $201.2 \pm 26.6$ & $193 \pm 21.4$ & $241 \pm 33.4$ & 0.304 & $<0.001$ & $<0.001$ \\
\hline \multicolumn{7}{|l|}{ TG $[\mathrm{mg} / \mathrm{dL}]$} \\
\hline Mean \pm SD & $131.6 \pm 26.6$ & $166.1 \pm 26.7$ & $151 \pm 29.2$ & $<0.001$ & 0.002 & 0.0581 \\
\hline \multicolumn{7}{|l|}{ HDL-C [mg/dL] } \\
\hline Mean \pm SD & $55.8 \pm 4.1$ & $55.5 \pm 4.2$ & $45.3 \pm 5.1$ & 0.948 & $<0.001$ & $<0.001$ \\
\hline \multicolumn{7}{|l|}{ LDL-C [mg/dL] } \\
\hline Mean \pm SD & $105.3 \pm 13.2$ & $105.2 \pm 17.5$ & $107.7 \pm 7.6$ & 0.999 & 0.653 & 0.624 \\
\hline \multicolumn{7}{|l|}{ CRP $[\mathrm{mg} / \mathrm{dL}]$} \\
\hline Mean \pm SD & $4.6 \pm 2.4$ & $5 \pm 2.8$ & $8.2 \pm 5.1$ & 0.557 & $<0.001$ & $<0.001$ \\
\hline \multicolumn{7}{|l|}{ IL6 [mg/dL] } \\
\hline Mean \pm SD & $31.5 \pm 14.4$ & $31.7 \pm 12$ & $43.1 \pm 16.3$ & 0.807 & $<0.001$ & $<0.001$ \\
\hline \multicolumn{7}{|l|}{ TNF- $\alpha[\mathrm{mg} / \mathrm{dL}]$} \\
\hline Mean \pm SD & $16.5 \pm 1.5$ & $17.1 \pm 1$ & $18.1 \pm 0.8$ & $<0.001$ & $<0.001$ & $<0.001$ \\
\hline
\end{tabular}

2hPP: 2 hours postprandial blood glucose; BMI: body mass index; CRP: C-reactive protein; FBG: fasting blood glucose; HbA 1 : glycated hemoglobin; HDL-C: high-density lipoprotein cholesterol; IL6: interleukin 6; LDL-C: low-density lipoprotein cholesterol

TG: triglycerides; TNF- $\alpha$ : tumor necrosis factor alpha

$\mathrm{P}_{1}$ : $\mathrm{P}$ value for comparing between Yogurt and diet group and Yeast and diet group

$\mathrm{P}_{2}$ : $\mathrm{P}$ value for comparing between Yogurt and diet group and Diet only group

$P_{3}$ : $P$ value for comparing between Yeast and diet group and Diet only group

Statistically significant at $P \leq 0.05$ 
The results of a meta-analysis including twelve RCTs involving 770 participants by Hu et al. [41] showed that probiotics could significantly reduce fasting blood glucose and HOMA-IR of patients with T2DM. Results also confirmed the significant lowering effect of probiotics on total cholesterol and as well as the elevating effect on HDL-c but with no significant change on LDL-C.

As the gut microbiota is a main source of endotoxin, treatment with probiotics may influence the circulating levels of endotoxin by altering the microbiota composition. To date, relatively few studies have examined the effects of endotoxin in metabolic diseases using probiotics. To expand on these earlier findings, the present study explored the potential beneficial effects of probiotics on circulating endotoxin levels and other markers for systemic low-grade inflammation in patients with T2DM.

In our study all aspects of inflammatory markers which were investigated were changed in the patients who had probiotics. CRP, IL-6 and TNF- levels were reduced significantly in both groups who received probiotics on a daily basis with no reduction in those who didn't receive probiotics. Our study agrees with a double-blind, placebo-controlled trial that showed that the serum concentrations of hs-CRP, IL- 6 and TNFdecreased significantly in patients receiving synbiotics for 8 weeks compared to baseline [42].

Probiotic bacteria (with the best documented strains being species of Lactobacillus or Bifidobacterium) can inhibit the growth of pathogenic bacteria by acidifying the gut lumen, competing for nutrients, and producing antimicrobial substances. Furthermore, they adhere to the gastrointestinal mucosa and are thought to prevent bacterial translocation from the gut [43, 44]. However, not all studies have shown beneficial effects of probiotics, and thus caution should be taken in terms of the dosage and strains to be used, as these may have important ramifications on the effects observed.

\section{Conclusion}

In summary, we expect that our findings will demonstrate that probiotics alter gut microbiota in T2DM and that, in theory, the alterations will be metabolically favorable with continued probiotic use. The results of our study showed that the administration of probiotics daily for 16 weeks could result in improvement of FBG, postprandial blood glucose, HbA1c, lipid profile and reduction in inflammatory markers in patients with T2DM and thus probiotics can be a promising beneficial adjuvant in T2DM. However, further studies on larger scales will be needed to demonstrate whether the efficacy of the probiotics used in this study can be extended further levels.

\section{Acknowledgements}

We thank the nutrition department, High Institute of Public Health and diabetes unit, Faculty of Medicine, Alexandria University

\section{Conflict of interest}

The authors declare no conflict of interest.

\section{REFERENCES:}

1. American Diabetes Association. 5. Facilitating Behavior Change and Well-being to Improve Health Outcomes: . Diabetes Care. 2020; 43(Suppl 1): S48-S65, doi: 10.2337/dc20-S005, indexed in Pubmed: 31862748.

2. Tabish SA. Is Diabetes Becoming the Biggest Epidemic of the Twenty-first Century? Int J Health Sci (Qassim). 2007; 1(2): V-VIII, indexed in Pubmed: 21475425.

3. Nolan C, Damm P, Prentki M. Type 2 diabetes across generations: from pathophysiology to prevention and management. The Lancet. 2011; 378(9786): 169-181, doi: 10.1016/s01406736(11)60614-4.

4. Kahn S, Cooper M, Prato SD. Pathophysiology and treatment of type 2 diabetes: perspectives on the past, present, and future. The Lancet. 2014; 383(9922): 1068-1083, doi: 10.1016/s01406736(13)62154-6.

5. Donath MY, Shoelson SE. Type 2 diabetes as an inflammatory disease. Nat Rev Immunol. 2011; 11(2): 98-107, doi: 10.1038/ nri2925, indexed in Pubmed: 21233852.

6. Doi Y, Kiyohara Y, Kubo M, et al. Elevated C-reactive protein is a predictor of the development of diabetes in a general Japanese population: the Hisayama Study. Diabetes Care. 2005; 28(10): 2497-2500, doi: 10.2337/diacare.28.10.2497, indexed in Pubmed: 16186286.

7. Marques-Vidal $P$, Bastardot $F$, von Känel $R$, et al. Association between circulating cytokine levels, diabetes and insulin resistance in a population-based sample (CoLaus study). Clin Endocrinol (Oxf). 2013; 78(2): 232-241, doi: 10.1111/j.1365-2265.2012.04384.x, indexed in Pubmed: 22409372.

8. Nadeem A, Naveed AK, Hussain MM, et al. Correlation of inflammatory markers with type 2 Diabetes Mellitus in Pakistani patients. Journal of Postgraduate Medical Institute (Peshawar-Pakistan). 2013; 27(3).

9. Festa A, D'Agostino R, Tracy RP, et al. Insulin Resistance Atherosclerosis Study. Elevated levels of acute-phase proteins and plasminogen activator inhibitor-1 predict the development of type 2 diabetes: the insulin resistance atherosclerosis study. Diabetes. 2002; 51(4): 1131-1137, doi: 10.2337/diabetes.51.4.1131, indexed in Pubmed: 11916936.

10. Mirza S, Hossain M, Mathews $C$, et al. Type 2-diabetes is associated with elevated levels of TNF-alpha, IL- 6 and adiponectin and low levels of leptin in a population of Mexican Americans: a crosssectional study. Cytokine. 2012; 57(1): 136-142, doi: 10.1016/j. cyto.2011.09.029, indexed in Pubmed: 22035595.

11. Varghese A, Asha NS, Celine TM, et al. Inflammatory markers in type II diabetes mellitus. The Pharma Innovation. 2015; 4(7, Part B): 64.

12. Calle MC, Fernandez ML. Inflammation and type 2 diabetes. Diabetes Metab. 2012; 38(3): 183-191, doi: 10.1016/j.diabet.2011.11.006, indexed in Pubmed: 22252015.

13. Al-Shukaili A, Al-Ghafri S, Al-Marhoobi S, et al. Analysis of inflammatory mediators in type 2 diabetes patients. Int J Endocrinol. 2013; 2013: 976810, doi: 10.1155/2013/976810, indexed in Pubmed: 23762057.

14. Pickup JC. Inflammation and activated innate immunity in the pathogenesis of type 2 diabetes. Diabetes Care. 2004; 27(3): 813-823, doi: 10.2337/diacare.27.3.813, indexed in Pubmed: 14988310. 
15. Rinninella $E$, Raoul $P$, Cintoni $M$, et al. What is the Healthy Gut Microbiota Composition? A Changing Ecosystem across Age, Environment, Diet, and Diseases. Microorganisms. 2019; 7(1), doi: 10.3390/microorganisms7010014, indexed in Pubmed: 30634578.

16. Rothschild D, Weissbrod O, Barkan E, et al. Environment dominates over host genetics in shaping human gut microbiota. Nature. 2018; 555(7695): 210-215, doi: 10.1038/nature25973, indexed in Pubmed: 29489753.

17. Valdes AM, Walter J, Segal E, et al. Role of the gut microbiota in nutrition and health. BMJ. 2018; 361: k2179, doi: 10.1136/bmj. k2179, indexed in Pubmed: 29899036.

18. Lu J, Ma K, Ruan X. Dysbiosis of Gut Microbiota Contributes to the Development of Diabetes Mellitus. Infectious Microbes and Diseases. 2019; 1(2): 43-48, doi: 10.1097/im9.0000000000000011.

19. Gurung M, Li Z, You H, et al. Role of gut microbiota in type 2 diabetes pathophysiology. EBioMedicine. 2020; 51: 102590, doi: 10.1016/j.ebiom.2019.11.051, indexed in Pubmed: 31901868.

20. Boutagy NE, McMillan RP, Frisard MI, et al. Metabolic endotoxemia with obesity: Is it real and is it relevant? Biochimie. 2016; 124: 11-20, doi: 10.1016/j.biochi.2015.06.020, indexed in Pubmed: 26133659.

21. Cani PD, Possemiers $S$, Van de Wiele T, et al. Changes in gut microbiota control inflammation in obese mice through a mechanism involving GLP-2-driven improvement of gut permeability. Gut. 2009; 58(8): 1091-1103, doi: 10.1136/gut.2008.165886, indexed in Pubmed: 19240062.

22. Kurtzman CP, Fell JW. Biodiversity and ecophysiology of yeasts. In: Gábor P, de la Rosa CL. ed. The Yeast Handbook. Springer, Berlin 2005: 11-30.

23. Didari T, Solki S, Mozaffari S, et al. A systematic review of the safety of probiotics. Expert Opin Drug Saf. 2014; 13(2): 227-239, doi: 10.1517/14740338.2014.872627, indexed in Pubmed: 24405164.

24. Czerucka D, Piche T, Rampal P. Yeast as probiotics-Saccharomyces boulardii. Alimentary pharmacology \& therapeutics. 2007; 26(6): 767-778.

25. Smith IM, Baker A, Arneborg N, et al. Non-Saccharomyces yeasts protect against epithelial cell barrier disruption induced by Salmonella enterica subsp. enterica serovar Typhimurium. Lett Appl Microbiol. 2015; 61(5): 491-497, doi: 10.1111/lam.12481, indexed in Pubmed: 26280244.

26. Saber A, Alipour B, Faghfoori Z, et al. Cellular and molecular effects of yeast probiotics on cancer. Crit Rev Microbiol. 2017; 43(1): 96-115, doi: 10.1080/1040841X.2016.1179622, indexed in Pubmed: 27561003.

27. Kocsis $T$, Molnár $B$, Németh $D$, et al. Probiotics have beneficial metabolic effects in patients with type 2 diabetes mellitus: a metaanalysis of randomized clinical trials. Sci Rep. 2020; 10(1): 11787, doi: 10.1038/s41598-020-68440-1, indexed in Pubmed: 32678128.

28. Tabuchi M, Ozaki M, Tamura A, et al. Antidiabetic effect of Lactobacillus GG in streptozotocin-induced diabetic rats. Biosci Biotechnol Biochem. 2003; 67(6): 1421-1424, doi: 10.1271/ bbb.67.1421, indexed in Pubmed: 12843677.

29. Al-Salami H, Butt G, Fawcett JP, et al. Probiotic treatment reduces blood glucose levels and increases systemic absorption of gliclazide in diabetic rats. Eur J Drug Metab Pharmacokinet. 2008; 33(2): 101-106, doi: 10.1007/BF03191026, indexed in Pubmed: 18777945

30. Yun SI, Park HO, Kang JH. Effect of Lactobacillus gasseri BNR17 on blood glucose levels and body weight in a mouse model of type 2 diabetes. J Clin Diagn Res. 2009; 107(5): 1681-1686.
31. Yao K, Zeng L, He Q, et al. Effect of probiotics on glucose and lipid metabolism in type 2 diabetes mellitus: a meta-analysis of 12 randomized controlled trials. Med Sci Monit. 2017; 23 : 3044-3053, doi: 10.12659/msm.902600, indexed in Pubmed: 28638006

32. Sun J, Buys NJ. Glucose- and glycaemic factor-lowering effects of probiotics on diabetes: a meta-analysis of randomised placebocontrolled trials. Br J Nutr. 2016; 115(7): 1167-1177, doi: 10.1017/ S0007114516000076, indexed in Pubmed: 26899960.

33. Zhang Q, Wu Y, Fei X. Effect of probiotics on glucose metabolism in patients with type 2 diabetes mellitus: A meta-analysis of randomized controlled trials. Medicina (Kaunas). 2016; 52(1): 28-34, doi: 10.1016/j.medici.2015.11.008, indexed in Pubmed: 26987497.

34. Mifflin MD, St Jeor ST, Hill LA, et al. A new predictive equation for resting energy expenditure in healthy individuals. Am J Clin Nutr. 1990; 51(2): 241-247, doi: 10.1093/ajcn/51.2.241, indexed in Pubmed: 2305711.

35. Li C, Li X, Han H, et al. Effect of probiotics on metabolic profiles in type 2 diabetes mellitus: A meta-analysis of randomized, controlled trials. Medicine (Baltimore). 2016; 95(26): e4088, doi: 10.1097/MD.0000000000004088, indexed in Pubmed: 27368052.

36. Martin AM, Sun EW, Rogers GB, et al. The Influence of the Gut Microbiome on Host Metabolism Through the Regulation of Gut Hormone Release. Front Physiol. 2019; 10: 428, doi: 10.3389/ fphys.2019.00428, indexed in Pubmed: 31057420.

37. Gérard C, Vidal H. Impact of gut microbiota on host glycemic control. Front Endocrinol (Lausanne). 2019; 10: 29, doi: 10.3389/ fendo.2019.00029, indexed in Pubmed: 30761090.

38. Guo Z, Liu XM, Zhang QX, et al. Influence of consumption of probiotics on the plasma lipid profile: a meta-analysis of randomised controlled trials. Nutr Metab Cardiovasc Dis. 2011; 21(11): 844-850, doi: 10.1016/j.numecd.2011.04.008, indexed in Pubmed: 21930366.

39. Patel AK, Singhania RR, Pandey A, et al. Probiotic bile salt hydrolase: current developments and perspectives. Appl Biochem Biotechnol. 2010; 162(1): 166-180, doi: 10.1007/s12010-0098738-1, indexed in Pubmed: 19669939.

40. Ejtahed HS, Mohtadi-Nia J, Homayouni-Rad A, et al. Effect of probiotic yogurt containing Lactobacillus acidophilus and Bifidobacterium lactis on lipid profile in individuals with type 2 diabetes mellitus. J Dairy Sci. 2011; 94(7): 3288-3294, doi: 10.3168/ jds.2010-4128, indexed in Pubmed: 21700013.

41. Hu Ym, Zhou F, Yuan Y, et al. Effects of probiotics supplement in patients with type 2 diabetes mellitus: A meta-analysis of randomized trials. Medicina Clínica (English Edition). 2017; 148(8): 362-370, doi: 10.1016/j.medcle.2017.03.003.

42. Akram Kooshki A, Tofighiyan T, Rakhshani MH. Effects of Synbiotics on Inflammatory Markers in Patients With Type 2 Diabetes Mellitus. Glob J Health Sci. 2015; 7 (7 Spec No): 1-5, doi: 10.5539/ gjhs.v7n7p1, indexed in Pubmed: 26153197.

43. Gorbach SL. Probiotics and gastrointestinal health. Am J Gastroenterol. 2000; 95(1 Suppl): S2-S4, doi: 10.1016/s00029270(99)00806-0, indexed in Pubmed: 10634218.

44. Chiva M, Soriano G, Rochat I, et al. Effect of Lactobacillus johnsonii La1 and antioxidants on intestinal flora and bacterial translocation in rats with experimental cirrhosis. J Hepatol. 2002; 37(4): 456-462, doi: 10.1016/s0168-8278(02)00142-3, indexed in Pubmed: 12217598. 